\title{
Effect of impact parameters and moisture content on kernel loss during corn snapping**
}

\author{
Qiankun $\mathrm{Fu}^{1,2}$, Jun $\mathrm{Fu}^{1,2,3}$, Zhi Chen ${ }^{2,4}$, Lujia Han ${ }^{3}$, and Luquan Ren ${ }^{1,2}$ \\ ${ }^{1}$ College of Biological and Agricultural Engineering, ${ }^{2}$ Key Laboratory of Bionics Engineering, Ministry of Education; \\ Jilin University, Changchun 130022, China \\ ${ }^{3}$ College of Engineering, China Agricultural University, Beijing 100083, China \\ ${ }^{4}$ Chinese Academy of Agricultural Mechanization Sciences, Beijing 100083, China \\ Received January 26, 2019; accepted May 22, 2019
}

\begin{abstract}
This paper seeks to describe the effect of impact parameters and moisture content on kernel detachment, with the physical parameter of dissipated momentum being introduced to the process of analysing the data. Experiments were carried out on a drop-testing bed, using an accelerometer bound to corn ears to determine the impact parameters. As the impact velocity increased from 3.5 to $6.0 \mathrm{~m} \mathrm{~s}^{-1}$ at a moisture content of $18.5 \%$, peak acceleration, the integral of acceleration and rebound velocity increased simultaneously, while impact time showed a declining trend. The mass of the detached kernels increased from 5.13 to $13.70 \mathrm{~g}$ per corn ear. When the moisture content of the kernels increased from 11.8 to $30.6 \%$ with an impact velocity of $5.0 \mathrm{~m} \mathrm{~s}^{-1}$, the mass of the detached kernels decreased from 12.61 to $7.56 \mathrm{~g}$ per corn ear. The dissipated momentum showed homologous trends with that of the detached kernel mass. Furthermore, a model of the interaction effect of impact velocity and moisture content on the mass of the detached kernel was established through full factorialtests. The methods and data may provide theoretical guidance for the design and optimization of deck plates on the corn heads and decrease the incidence of kernel detachment.

Keywords: impact, kernels detachment, moisture content, corn ear snapping
\end{abstract}

\section{INTRODUCTION}

The main function of the harvester head is to employ a fracture separation load on the corn ears. The use of a corn harvester may significantly improve harvesting efficiency, but it also simultaneously induces a significant amount of kernel loss (Hanna et al., 2002). Impacts between the corn

\footnotetext{
*Corresponding author e-mail: fu_jun@jlu.edu.cn

**This work was supported by the National Natural Science Foundation of China (51705193) (2018-2020), the Science and Technology Development Project of Jilin Province (20170204016NY) (2017-2019) and the Graduate Innovation Fund of Jilin University (101832018C008) (2018-2019).
}

ears and deck plates are produced during corn ear snapping at the harvester head, which is the primary reason for kernel loss (Paulsen et al., 2013).

Based on the principle of avoiding unnecessary impact or reducing the impact level, many mechanical improvements to crop harvesters have been made in order to reduce kernel loss (Špokas et al., 2008; Zareiforoush et al., 2010; Fu et al., 2018). Many of these improvements were made to improve the mechanical process of corn ear snapping. Taking biological surface as the object, He (2007) designed two counter-rotating snapping rolls fitted with bionic structures of humps and holes, which aggressively pulled the corn stalks downward in a controlled motion. Yan (2009) found that a vertical roll-type corn harvester could effectively decrease kernel loss by reducing the required pull force on the corn ears. Furthermore, Wang et al. (2016) designed a pair of rib-snapping rollers with variable screw pitch that not only solved the problem of snapping-roller blockage but also reduced grain loss when the corn ear became overripe. In addition, Oxbo's 3000 series corn heads, John Deere's 700C series corn heads and Drago GT developed automatic self-adjusting devices to reduce ear impacts on the deck plates (Yang et al., 2016). However, the mechanical structures of these harvester heads were designed empirically, without further research into the mechanism of the impacts affecting kernel detachment.

On the other hand, some techniques were used to explore the relationship between impacts and the resulting damage on a variety of agricultural products (Studman, 2001; Li et al. 2009; Stropek and Gołacki, 2016). The changes,

(C) 2019 Institute of Agrophysics, Polish Academy of Sciences 


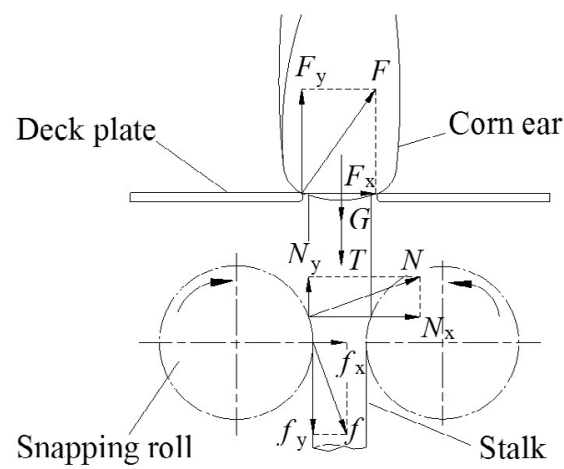

Fig. 1. Force diagram of corn ear detachment: $T$ - tensile force to corn ear, $G$ - gravity of corn ear, $F$ - resistance force of the deck plate on the corn ear, $F_{\mathrm{x}}$ - component of $F$ in the horizontal direction, $F_{\mathrm{y}}$ - component of $F$ in the vertical direction, $N$ - reaction force of the snapping roll on the stalk, $N_{\mathrm{x}}$ - component of $N$ in the horizontal direction, $N_{\mathrm{y}}$ - component of $N$ in the vertical direction, $f$ - friction force of the snapping roll on the stalk, $f_{\mathrm{x}}$ - component of $f$ in the horizontal direction, $f_{\mathrm{y}}-$ component of $f$ in the vertical direction.

a

b
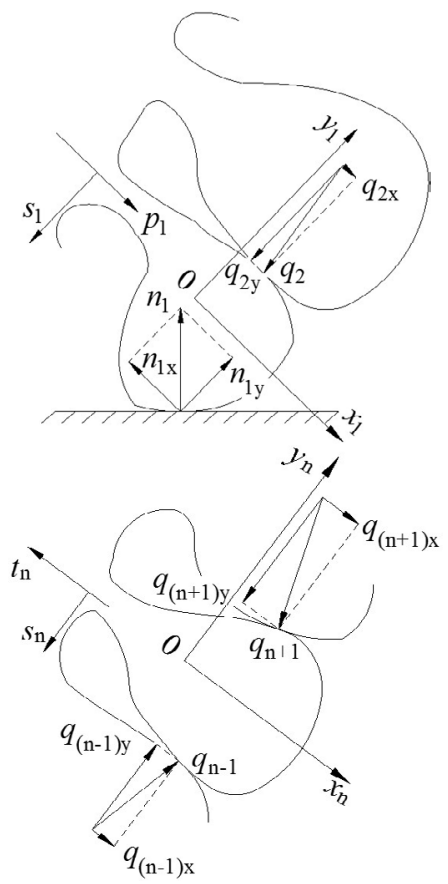

Fig. 2. Force diagram of corn kernels: a - force diagram of kernels in contact with the deck plate, $p_{1}-$ reaction force from the pedicel, $s_{1}$ - shear force from the pedicel, o $x_{1} y_{1}$ - floating coordinate system on the kernel in contact with the deck plate, $n_{1}$ - reaction force of the deck plate, $n_{1 \mathrm{x}}$ - component of $n_{1}$ in the direction of $x_{1}, n_{1 y}$ - component of $n_{1}$ in the direction of $y_{1}, q_{2}$ - reaction force of the next kernel, $q_{2 x}$ - component of $q_{2}$ in the direction of $x_{1}$, $q_{2 y}$ - component of $q_{2}$ in the direction of $y_{1} ; \mathrm{b}$ - force diagram of kernel not in contact with the deck plate, $t_{\mathrm{n}}$ - tensile force from the pedicel, $s_{\mathrm{n}}$ - shear force from the pedicel, o $x_{\mathrm{n}} y_{\mathrm{n}}$ - floating coordinate system on the kernel not in contact with the deck plate, $q_{\mathrm{n}-1}$ - reaction force from the nether kernel, $q_{(\mathrm{n}-1) \mathrm{x}}-$ component of $q_{\mathrm{n}-1}$ in the direction of $x_{\mathrm{n}}, q_{(\mathrm{n}-1) \mathrm{y}}-$ component of $q_{\mathrm{n}-1}$ in the direction of $y_{\mathrm{n}}, q_{\mathrm{n}+1}-$ reaction force from the upper kernel, $q_{(\mathrm{n}+1) \mathrm{x}}-$ component of $q_{\mathrm{n}+1}$ in the direction of $x_{\mathrm{n}}, q_{(\mathrm{n}+1) \mathrm{y}}-$ component of $q_{\mathrm{n}+1}$ in the direction of $y_{\mathrm{n}}$. which occurred in impact force, impact time and acceleration, as well as those, which occurred in the mechanical properties of fruit within those parameters, were the main issues included in the work of some significant researchers (Lu et al., 2010; Jiménez-Jiménez et al., 2012; Boydas et al., 2014; Stropek and Gołacki, 2015). The mechanical properties of grain crops in particular varied with their moisture content (Srivastava et al., 1976; Shahbazi 2011; Shahbazi et al., 2011), which differed from those of fresh fruits. Burkhardt and Stout (1974) measured the maximum impact force inflicted on corn ears, and found that the peak force was dependent on moisture content, ear weight, and impact velocity. Li et al. (2014) dropped impact heads on fixed corn ears over a range of moisture contents, the results showed the discrete effect of kernels is reduced with the increase in moisture. Moreover, Singh et al. (1991) tested the elastic modulus and Poisson's ratio under different moisture contents and revealed the stress and strain law of kernel detachment. Kalkan et al. (2011) found that the strength values of popcorn decreased with increasing moisture content by measuring strength properties and the dynamic coefficient of friction. Ajayi and Clarke (1997) found that moisture content had the most significant effect on the strength characteristics of the corn kernel by assessing the energy of impact loss. Therefore, the moisture content of kernels was an indispensable factor in the analysis of corn-snapping impact parameters.

In the process of corn ear snapping, each corn ear was moved vertically downward at a speed equal to the linear velocity of the snapping rolls before colliding with the deck plates. When it made contact with the deck plates, the corn ear was subjected to tensile force $T$, gravity $G$ and resistance $F$ from deck plates as shown in Fig. 1 (Zhao, 2012). At the same time, the velocity of the corn ear abruptly dropped to zero with huge deceleration, which was numerically proportional to the impact forces involved (Yousefi et al., 2016). As a result, the kernels on the corn ear were detached from the cob, causing grain loss at the corn harvester head.

The pedicel forms the connection between the cob and the kernel. The force diagram of the kernels is illustrated in Fig. 2. The kernels in direct contact with the deck plates (Fig. 2a), were subjected to the following forces: reaction force $p_{1}$ and shear force $s_{1}$ through the kernel pedicel, reaction forces $n_{1}$ from the deck plate and $q_{2}$ from the next kernel. A floating coordinate system was established for the kernel that we studied. Assuming that the direction of the kernel pedicel as the $x_{1}$ axis and the elevation direction as the $y_{1}$ axis, reaction forces $n_{1}$ and $q_{2}$ may be divided into their components $n_{1 x}, q_{2 x}$ in the direction of $x_{1}$ and $n_{1 y}, q_{2 y}$ in the direction of $y_{1}$ (Petrů et al., 2012; Xu et al., 2013; Qian et al., 2017). As the forces involved were conducted mainly along the axis direction of the corn cob, the detaching condition for the kernel may be expressed by the following inequality: 


$$
\left\{\begin{array}{l}
n_{1 x}-q_{2 x}-\mu q_{2 y}>P_{\mathrm{L}} \\
n_{1 y}-q_{2 y}>S_{\mathrm{L}}
\end{array}\right.
$$

where: $\mu$ is the coefficient of sliding friction; $P_{\mathrm{L}}$ is for reaction force limit in the direction of the pedicel, $S_{\mathrm{L}}$ is the shear force limit in the elevation direction of the pedicel.

For the kernels which weren't in contact with the deck plates (Fig. 2b), the forces applied to them were the tensile force $t_{\mathrm{n}}$, the shear force $s_{\mathrm{n}}$ through the kernel pedicel, and the reaction forces of the next kernels $q_{\mathrm{n}-1}$ and $q_{\mathrm{n}+1}$. Similarly, in the coordinate system o $x_{\mathrm{n}} y_{\mathrm{n}}$, the reaction forces $q_{n-1}$ and $q_{n+1}$ may be divided into $q_{(n-1) x}, q_{(n+1) x}$ in the direction of $x_{n}$, and $q_{(n-1) y}, q_{(n+1) y}$ in the directions of $y_{n}$. The detaching conditions of these kernels may be expressed with the following inequality:

$$
\left\{\begin{array}{l}
q_{(n-1) x}+q_{(n+1) x}-\mu q_{(n-1) y}-\mu q_{(n+1) y}>T_{\mathrm{L}}, \\
q_{(n-1) y}-q_{(n+1) y}>S_{\mathrm{L}}
\end{array}\right.
$$

where: $T_{\mathrm{L}}$ represents the tensile force limit in the direction of the pedicel.

The aim of this research was to determine the relationships between kernel detachment and the impacts parameters of corn ears on simulated deck plates. The impact parameters include impact time, peak acceleration, rebound velocity, and impact impulse. They were affected by impact velocity, as well as the moisture contents of the corn kernels. These parameters may be used to evaluate the effects of dissipated momentum in the impacts, which were closely related to kernel detachment. Furthermore, a model was constructed to relate kernels detachment to the interaction of the effects of impact velocity and moisture content. The proposed model may be used to guide the design of corn ear-snapping devices.

\section{MATERIALS AND METHODS}

The research was carried out on a corn variety named Zhengdan 958, which is widely planted in Northeast China. The corn ears were picked by hand in October 2018 from the Agricultural Experimental Base of Jilin University in Changchun, Jilin province. The moisture contents of the kernels were measured at $30.6 \%$. The corn ears used in the research had a uniform shape and size, there was no kernel crushing or shedding, no diseases or insect pests. All of the corn ears selected had a mass of 300-320 g, a maximum diameter of 50-54 mm and a length of 200-220 mm. Before the experiments, the husks of the corn ears were removed by hand. The peduncle residues were detached completely with a knife to eliminate their influence from the forces applied to the kernels.

A drop-testing bed was designed to test the impact parameters of the corn ears, as shown in Fig. 3a. The drop-testing bed included a motor-driven lifting screw to control the drop height. Two horizontal slide rails, two electric pushing rods, two supporting plates, and holding bars

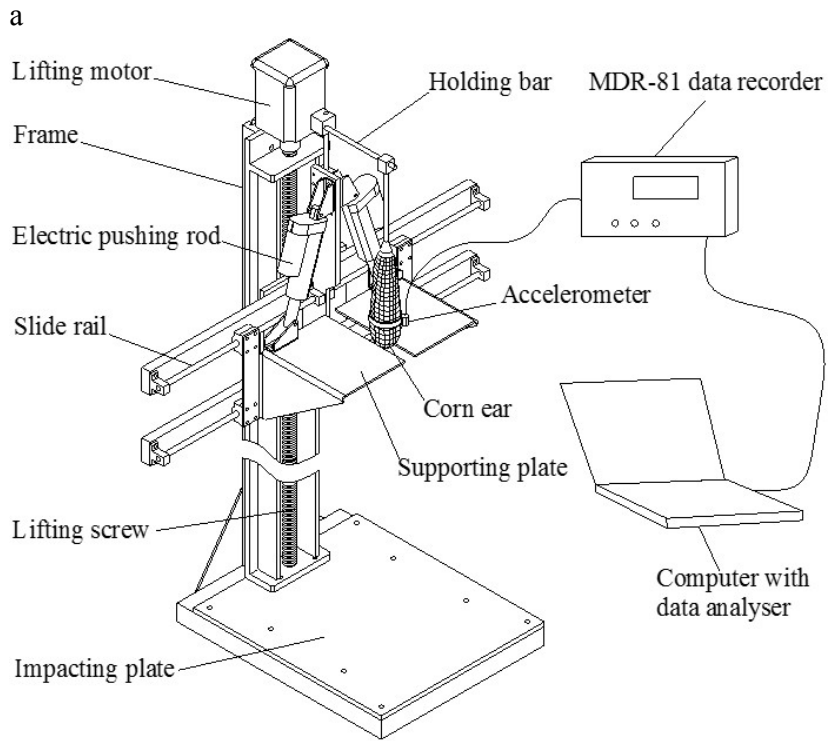

b

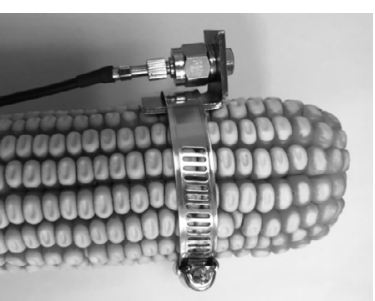

Fig. 3. Impact system of the corn ear: a - drop-testing bed of corn ear impact, $\mathrm{b}$ - corn ear fixed with an accelerometer.

were used to hold and release the corn ear. An impact plate at the base of the drop-testing bed was used as a substitute for the deck plates of the corn head. The corn ear was fixed precisely to the middle of supporting plates before being dropped down. A CA-YD-180c type accelerometer was screwed into a thick steel plate bonded to the corn ear with a hoop, as shown in Fig. 3b. The accelerometer had a sensitivity of $0.509 \mathrm{mV}\left(\mathrm{m} \mathrm{s}^{-2}\right)^{-1}$. The sampling frequency was $0-15000 \mathrm{~Hz}$, and the measurement range was $\pm 10000 \mathrm{~m} \mathrm{~s}^{-2}$. An MDR-81 data recorder and DDP data analyser were used to record and analyse the acceleration data respectively.

An accelerometer fixed at a distance of $30 \mathrm{~mm}$ from the lower end of the corn ear was used to measure the impact acceleration and impact time. The sampling frequency of the accelerometer was set to $10240 \mathrm{~Hz}$. In particular, some kernels on the corn ear top were removed to quantify the corn ears at a mass of $240 \mathrm{~g}$ under similar conditions. The total mass of the impacting objects was $275 \mathrm{~g}$, this includes the corn ear, accelerometer, steel plate, and the hoop. The operation described above aimed to reduce disturbances to the impact parameters caused by the mass fluctuation of the corn ears. The acceleration parameters could be used to determine the impact parameters including the impact time, peak acceleration, impact impulse, and rebound velocity. 
The detachment of the corn ears was accomplished in a short time period due to the high rotation speed of the snapping rolls. Because of the high impact velocities and flexibility of the colliding bodies, the impact of the corn ear on the deck plates was more complicated than the impact between the mass point and the plate. The impact process of the corn ear was in accordance with the momentumimpulse conservation law. As irreversible deformation was produced in the form of kernels detachment, the formula of momentum conservation law could be modified to the following form (Stropek and Gołacki, 2013):

$$
M \int_{t_{0}}^{t_{0}+\Delta t} a(t) \mathrm{d} t=M v_{\mathrm{I}}+M^{\prime} v_{\mathrm{R}}+P_{\mathrm{d}},
$$

where: $M$ is the corn ear mass before impact; $a$ is the acceleration; $M^{\prime}$ 'is the corn ear mass after impact; $v_{\mathrm{I}}$ is the impact velocity; $v_{R}$ is the rebound velocity; $P_{d}$ is the dissipated momentum of the corn ear; $t$ is time; $t_{0}$ is the time at which the corn ear touched the deck plates; $\Delta t$ is the impact time.

Impact time and peak acceleration were two important parameters chosen for the assessment of the mechanical impact strength. The impact time was the exact length of the time period from the rise of acceleration to its decrease to the level position. After digital filtering, a typical diagrammatic sketch of acceleration in the corn ear impact process was obtained as shown in Fig. 4. The impact time is $\Delta t$ in Fig. 4. It lasts from the upturn of acceleration to its decrease to the base value. The acceleration of gravity is so slight compared to the impact acceleration that it may be neglected in this process. The peak value of acceleration $a_{\mathrm{p}}$ indicates the peak force applied to the corn ear. The impact impulse is the product of the corn ear mass and the definite integral of acceleration from $a_{0}$ to $a_{0}+\Delta t$. The definite integral of acceleration may be calculated using graphing and analysis software ORIGIN 2017 by integrating the curve from $t_{0}$ to $t_{0}+\Delta t$.

The impact velocity was the linear velocity of the corn ears moving towards the deck plates. It equals the peripheral velocity of the outer margin of the snapping rolls. The velocity may be calculated using the following equation:

$$
v_{\mathrm{S}}=\frac{n \pi R}{60},
$$

where: $v_{\mathrm{S}}$ is the linear velocity of the corn ears; $n$ is the rotating speed of the snapping roll, ranging from 750 to $1050 \mathrm{rpm} ; R$ is the diameter of the snapping roll, which is approximately $100 \mathrm{~mm}$. Hence, the velocities of the corn ears before stripping may be calculated at 3.93 to $5.50 \mathrm{~m} \mathrm{~s}^{-1}$. In this experiment, the impact velocity may be determined by changing the drop height. Mathematically, this may be expressed as follows:

$$
v_{\mathrm{I}}=\sqrt{2 g h},
$$

where: $v_{\mathrm{I}}$ is the impact velocity, $\mathrm{m} \mathrm{s}^{-1} ; g$ is the acceleration due to gravity, with a value of $9.8 \mathrm{~m} \mathrm{~s}^{-2} ; h$ is the drop height from the lower end of the corn ear to the impact plate.

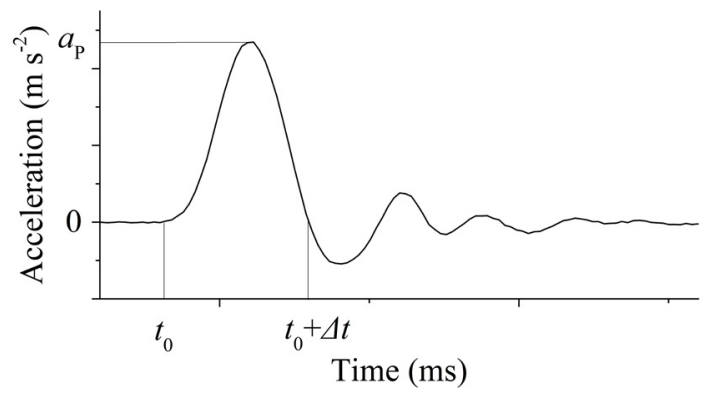

Fig. 4. Diagrammatic sketch of corn ear impact acceleration: $a_{P}$ - peak acceleration, $t_{0}$ - the time when the corn ear touched the deck plates, $\Delta t-$ the impact time.

The impacts were researched under six different velocity varieties: $3.5,4.0,4.5,5.0,5.5$ and $6.0 \mathrm{~m} \mathrm{~s}^{-1}$, corresponding to drop heights of $0.625,0.813,1.033,1.275$, 1.543 and $1.837 \mathrm{~m}$.

The corn ear was only subjected to gravity and reaction force during impact. Both of the forces occurred in the vertical direction. Accordingly, the rebound movement of the corn ear was in the upward direction vertically. Therefore, the rebound velocity could be calculated from the rebound time, which was the time difference between the first impact and the second impact. Figure 5 shows a diagram of acceleration from the first impact to the second impact. The rebound velocity may be calculated using the following equation:

$$
v_{\mathrm{R}}=\frac{1}{2} g\left(t_{2}-t_{1}\right),
$$

where, $v_{R}$ is the rebound velocity of the corn ear, $t_{1}$ is the moment of the first impact; $t_{2}$ is the moment of the second impact.

In this experiment, the main cause of the dissipated momentum was the detachment of the kernel. The impact velocity and the response to the impact, including the impact time, peak acceleration, impact impulse, and rebound velocity were used to estimate the dissipated momentum of the corn ear due to the impact.

In addition, the moisture content was controlled quantitatively. Different groups of corn ears were dried naturally in the air. The four moisture content degrees were 11.8, 18.5, 23.4 and $30.6 \%$ accordingly. The corn ears were provided with hermetic and cryogenic storage before the impact tests.

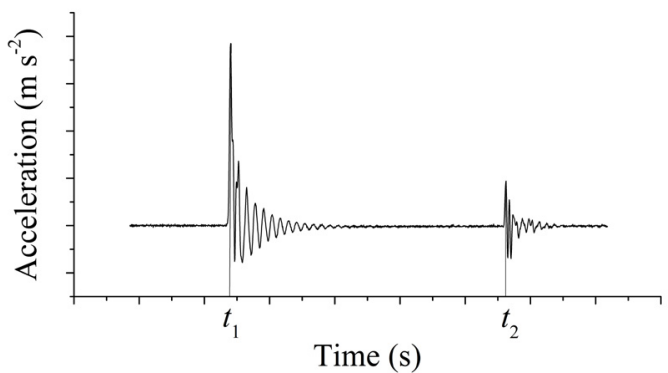

Fig. 5. Diagram of acceleration from the 1 st impact to the 2 nd impact: $t_{1}$ - the moment of the first impact, $t_{2}-$ the moment of the second impact. 
Over the course of the tests, measurements were conducted on 20 corn ears for each treatment. The masses of the detached kernels, as well as the numerical values of the impact times, peak acceleration, and rebound times were recorded on the spot. The impact impulse, rebound velocity, and dissipated momentum were calculated through the use of software and formulas.

\section{RESULTS AND DISCUSSION}

The relationship between peak acceleration and impact velocity is shown in Fig. 6a. Impact acceleration increased with the impact velocity. Specifically, as the impact velocity increased from 3.5 to $6.0 \mathrm{~m} \mathrm{~s}^{-1}$, the peak acceleration increased from 2072.2 to $3725.8 \mathrm{~m} \mathrm{~s}^{-2}$. In previous studies, the figures showed an analogous trend. According to Geyer et al. (2009), peak accelerations were approximately $1470 \mathrm{~m} \mathrm{~s}^{-2}$ for an impact velocity of $3.13 \mathrm{~m} \mathrm{~s}^{-1}$ and approximately $1960 \mathrm{~m} \mathrm{~s}^{-2}$ for a velocity of $4.43 \mathrm{~m} \mathrm{~s}^{-1}$ as measured by the acceleration measuring unit (AMU) placed in the

a

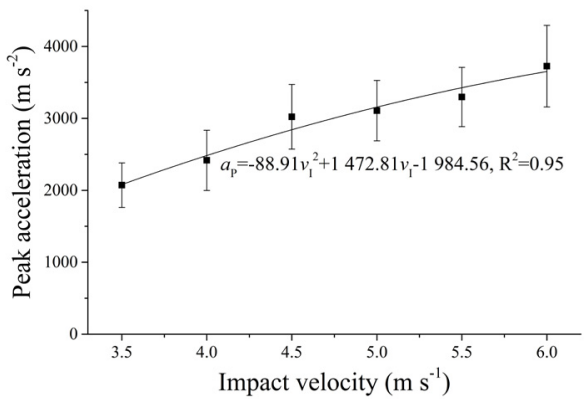

b

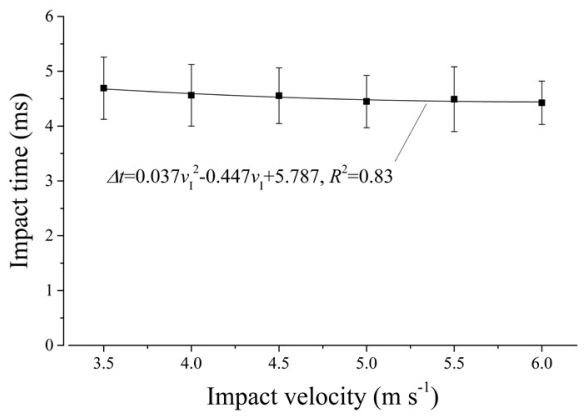

d

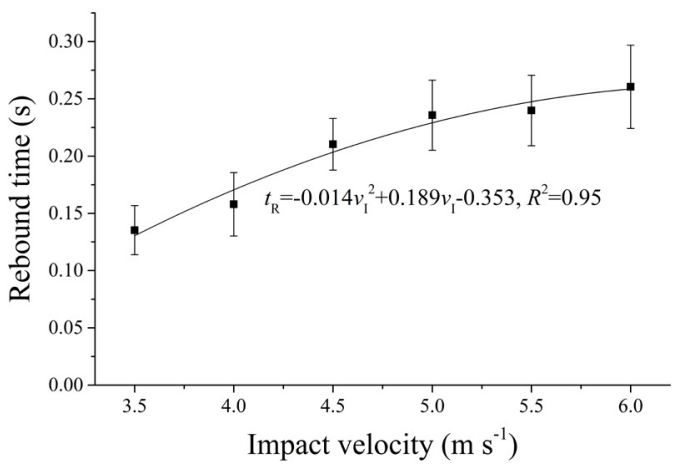

potato tubers. The results were thought to be diminished due to the uncontrolled movement of the AMU inside the tuber. Cerruto et al. (2015) also confirmed that peak acceleration increased with the impact velocity based on the finite element method.

The relationship between the impact time and impact velocity is demonstrated in Fig. 6b. Overall, the impact time showed a declining trend with the increase in impact velocity. As the impact velocity increased from 3.5 to $6 \mathrm{~m} \mathrm{~s}^{-1}$, the mean impact time dropped from 4.69 to $4.43 \mathrm{~ms}$. However, compared to the other fluctuations, the changes in impact times at different impact velocities were so slight, that the numerical values of the impact times in this test did not correspond strictly to the declining trend. For example, the impact time was $4.45 \mathrm{~ms}$ in the case of an impact velocity of $5.0 \mathrm{~m} \mathrm{~s}^{-1}$, but it increased to $4.49 \mathrm{~ms}$ in the case of $5.5 \mathrm{~m} \mathrm{~s}^{-1}$. In a previous work, Stropek and Gołacki (2013) measured an average impact time decrease from approximately $6.5 \mathrm{~ms}$ to approximately $4.5 \mathrm{~ms}$ as the impact velocity increased from 0.125 to $1.66 \mathrm{~m} \mathrm{~s}^{-1}$. The differences between the figures were caused by the material properties and velocity contrast (Lien and Ting, 2014; Cerruto et al. 2015; Lin and Zhang, 2017).

The product of corn ear mass and acceleration integral is used to determine the impact impulse of the corn ear. Since the mass of the impacting objects was quantified to $275 \mathrm{~g}$ in all the tests, the integral of acceleration was used as a quantitative reference indicating the impact impulse. The best fitting curve for the relationship between the acceleration integral and the impact velocity was a straight line,

c
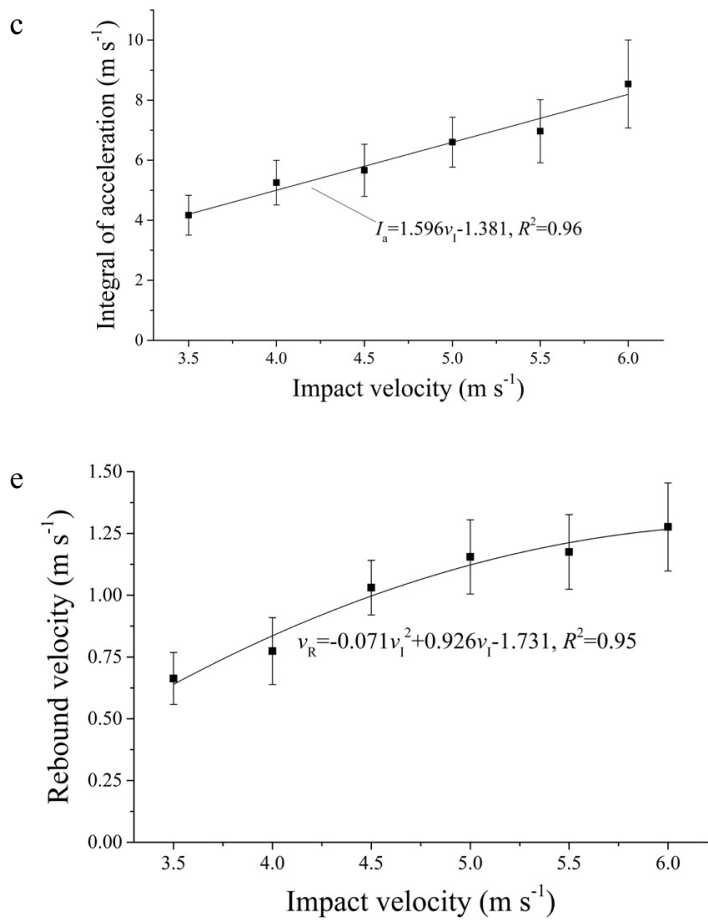

Fig. 6. Relationship between the rebound velocity and the impact parameters: a - peak acceleration $\left(a_{\mathrm{P}}\right), \mathrm{b}-$ impact time $(\Delta t), \mathrm{c}-$ integral of acceleration $\left(I_{\mathrm{a}}\right), \mathrm{d}$ - rebound time $\left(t_{R}\right), \mathrm{e}-$ rebound velocity $\left(v_{R}\right), v_{\mathrm{I}}$ - impact velocity. Error bars indicate standard deviations. 
as shown in Fig. 6c. The integral of acceleration increased from 4.17 to $8.54 \mathrm{~m} \mathrm{~s}^{-1}$ as the impact velocity increased from 3.5 to $6.0 \mathrm{~m} \mathrm{~s}^{-1}$. Similarly, Lin and Zhang (2017) tested acceleration by fixing an accelerometer to concrete blocks. They found that impulses calculated from the integral of acceleration increased almost linearly with increases in impact velocity ranging from 5 to $13 \mathrm{~m} \mathrm{~s}^{-1}$, which agreed well with the results of a model based on smooth particle hydrodynamics.

The rebound time between the first impact and the second impact at different impact velocities is shown in Fig. 6d. The vertical rebound velocity increased dramatically when the impact velocities were smaller than $5.0 \mathrm{~m}$ $\mathrm{s}^{-1}$. As the impact velocities became higher than $5.0 \mathrm{~m} \mathrm{~s}^{-1}$, the increasing level of the rebound velocity slowed down. Typically, the rebound time was $0.135 \mathrm{~s}$ when the impact velocity was $3.5 \mathrm{~m} \mathrm{~s}^{-1}$, and it increased to $0.236 \mathrm{~s}$ at an impact velocity of $5.0 \mathrm{~m} \mathrm{~s}^{-1}$, yet it reached a value of 0.261 $\mathrm{s}$ at an impact velocity of $6.0 \mathrm{~m} \mathrm{~s}^{-1}$. Based on Eq. (6), the vertical rebound velocities were calculated, as shown in Fig. 6e. Yang and Schrock (1994) took the ratio of the impact velocity and rebound velocity of the kernel as the index of energy loss. Their test results were much higher than those of the corn ears, as the detached kernels from the corn ears removed a massive proportion of the kinetic energy.

The test of impacts at different kernel moisture contents was conducted at an impact velocity of $5.0 \mathrm{~m} \mathrm{~s}^{-1}$. The impact parameters of corn ears at different moisture contents is shown in Table 1. The peak accelerations ranged from 3145.4 to $3007.4 \mathrm{~m} \mathrm{~s}^{-2}$ with a declining trend. The elastic modulus was reported to decrease significantly when the moisture content of the kernels became higher (Singh et al., 1991; Figueroa et al., 2011). Lien and Ting (2014) tested the peak impact forces of guavas at a range of maturity states with a constant drop height of $15 \mathrm{~mm}$. In the same way, the impact force decreased as ripening decreased the elastic modulus.

The impact times showed no significant differences as the moisture content increased from 11.8 to $23.4 \%$, the impact time remained steady between 4.45 to $4.69 \mathrm{~ms}$, but the value rose sharply to $5.13 \mathrm{~ms}$ when the moisture content increased to $30.6 \%$. In their research with guavas, Lien and Ting (2014) found that the softening of fruit with maturity prolonged the impact time. However, the influences of moisture content on the impact time of the corn ear require further research and more precise measurement, as the impact time of the corn ear is comprehensively affected by the elastic modulus of the kernels, the connection between the kernels and cob and the interaction of the kernels.

As the result of definite integral calculation, the values of the acceleration integral were almost constant when the moisture content increased, they were $6.57,6.60,6.45$ and $6.54 \mathrm{~m} \mathrm{~s}^{-1}$, respectively. It suggested that the kernel moisture had little influence on the impact impulse when the impact velocity kept constant.

However, the rebound time showed a phenomenal increase with the moisture content. The mean values of the rebound time were $0.218,0.236,0.243$ and $0.265 \mathrm{~s}$, corresponding to a moisture content of 11.8, 18.5, 23.4 and $30.6 \%$, respectively. As shown in Fig. 7, the average rebound velocities were calculated to be 1.07, 1.16, 1.19 and $1.30 \mathrm{~m} \mathrm{~s}^{-1}$ according to Eq. (6). In the research of Lien and Ting (2014), the rebound velocity of the guavas was reduced as the effects of maturity softened the fruit. The difference in the results was closely related to the kinetic energy that consumed by the detached kernels.

The masses of the detached kernels evidently increased with the impact velocity, as shown in Fig. 8. When the impact velocities were $3.5,4.0,4.5,5.0,5.5$ and $6.0 \mathrm{~m} \mathrm{~s}^{-1}$, the statistical averages of the masses of the detached kernels

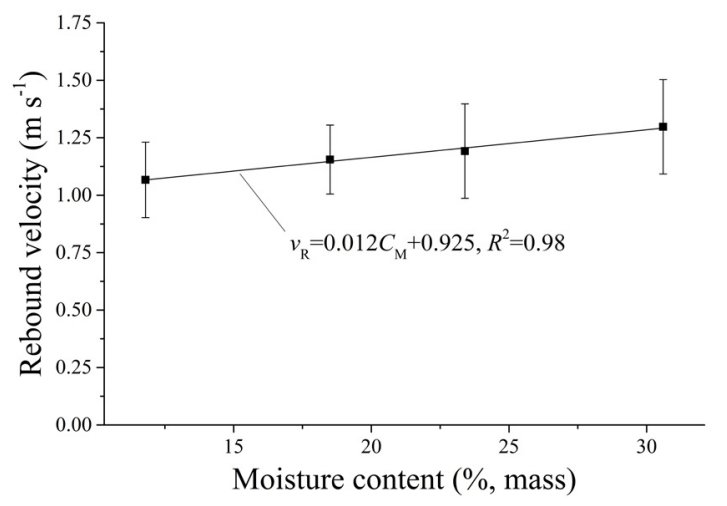

Fig. 7. Relationship between the rebound velocity and the moisture content, $C_{M}-$ moisture content. Other explanations as in Fig. 6. Error bars indicate standard deviations.

Table 1. Impact parameters of corn ears at different kernel moisture content

\begin{tabular}{ccccc}
\hline$C_{M}(\%)$ & $a_{P}\left(\mathrm{~m} \mathrm{~s}^{-2}\right)$ & $\Delta t(\mathrm{~ms})$ & $I_{a}\left(\mathrm{~m} \mathrm{~s}^{-1}\right)$ & $t_{R}(\mathrm{~s})$ \\
\hline 11.8 & $3145.4 \pm 399.9$ & $4.60 \pm 0.39$ & $6.57 \pm 0.91$ & $0.218 \pm 0.034$ \\
18.5 & $3107.8 \pm 419.9$ & $4.45 \pm 0.48$ & $6.60 \pm 0.83$ & $0.236 \pm 0.031$ \\
23.4 & $3081.8 \pm 534.8$ & $4.68 \pm 0.45$ & $6.45 \pm 0.85$ & $0.243 \pm 0.042$ \\
30.6 & $3007.4 \pm 478.2$ & $5.13 \pm 0.62$ & $6.54 \pm 0.76$ & $0.265 \pm 0.042$ \\
\hline
\end{tabular}

$C_{M}$ - kernel moisture content, $a_{P}$ - peak acceleration, $\Delta t$-impact time, $I_{a}-$ integral of acceleration, $t_{R}-$ rebound time. Data in the table are means \pm SD. 
were $5.13,5.49,6.68,9.99,11.01$ and $13.70 \mathrm{~g}$, respectively. As the impact velocity became higher, the increase in the mass of the detached kernels became more noticeable. The best-fit model for the mass of the detached kernels were 2-th curves. The effect of the impact velocity on kernel detachment was in accordance with that found for Špokas et al. (2008), Srison et al. (2016) and Fu et al. (2018).

According to the aforementioned Eq. (3), the dissipated momentum of the corn ears could be calculated. When the impact velocities were $3.5,4.0,4.5,5.0,5.5$ and $6.0 \mathrm{~m} \mathrm{~s}^{-1}$, the dissipated momentum values were $0.005,0.136,0.044$, $0.134,0.093$ and $0.365 \mathrm{~kg} \mathrm{~m} \mathrm{~s}^{-1}$, respectively. In order to show the trend of dissipated momentum with the impact velocities, a quadric fitting curve was obtained, as demonstrated in Fig. 8. The errors of the model were mainly from

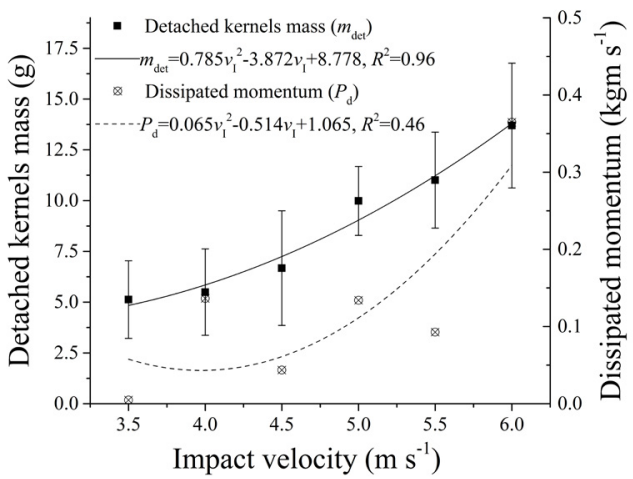

Fig. 8. Detached kernel mass and the dissipated momentum at different impact velocities. Explanations as in Fig. 6. Error bars indicate standard deviations.

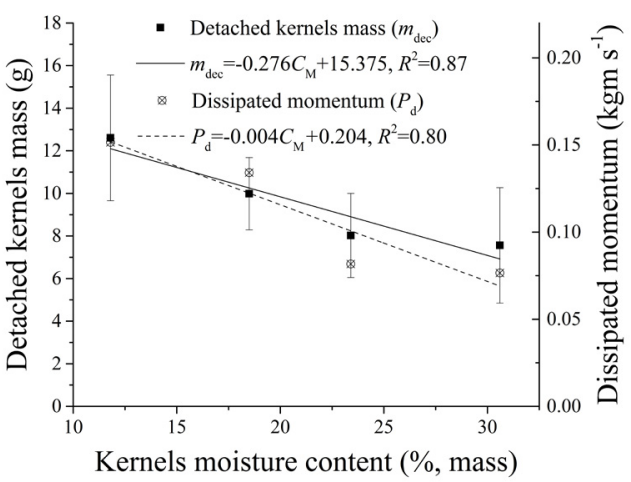

Fig. 9. Detached kernel mass and the dissipated momentum at different moisture content values. Explanations as in Fig. 7. Error bars indicate standard deviations. measurement errors of the rebound velocities and random errors. However, by dividing the dissipated momentum by the mass of the detached kernels, the quotient could also be used to estimate the mean launch velocities of the detached kernels.

On the other hand, the mass of the detached kernels decreased with the increase in the moisture content, as shown in Fig. 9. When the impact velocity was $5.0 \mathrm{~m} \mathrm{~s}^{-1}$, the average masses of the detached kernels were 12.61, $9.99,8.03$ and $7.56 \mathrm{~g}$, which corresponded to moisture contents of $11.8,18.5,23.4$ and $30.6 \%$, respectively. A linear model fitted well with the function of the moisture content in the detachment of the kernel. Similarly, the dissipated momentum of the corn ears decreased with the moisture content, as shown in Fig. 9. The values of the dissipated momentum were $0.152,0.134,0.082$ and $0.077 \mathrm{~kg} \mathrm{~m} \mathrm{~s}^{-1}$. Increasing the moisture content decreased the mass of the detached kernels, as the high moisture content strengthened the internal friction between the kernels and the connection between the kernels and the cobs (Burkhardt and Stout, 1974; Zhao, 2012; Li et al., 2014; Srison et al., 2016).

Figure 10 shows the corn ears after kernel detachment under different impact velocities at a moisture content of $18.5 \%$. It may be seen in the photographs that the detachment of the kernels had different features as the impact velocity increased. The detached kernels were well distributed around the lower end of the corn cob when the impact velocity was lower than $4.5 \mathrm{~m} \mathrm{~s}^{-1}$. As the impact velocity increased to over $5.0 \mathrm{~m} \mathrm{~s}^{-1}$, it turns out that the detached kernels form a ring around the bottom of the corn cob and there is a chain-like distribution on the corn ear midsection. The kernels in contact with the impacting plate in Fig. $2 \mathrm{a}$ as well as the ones that were not in contact with the impacting plate in Fig. 2b, were all detached from the corn cob. In addition, the forces applied to the kernels met Inequality (1) for the lower impact velocities. For velocities larger than $5.0 \mathrm{~m} \mathrm{~s}^{-1}$, Inequality (1) and (2) were satisfied simultaneously.

Similarly, the detachment of the kernel had different features with the increase in moisture content. Although the peak accelerations and acceleration integrals changed little with moisture content, as shown in Table 1, the masses of the detached kernels decreased notably with the increase in moisture content. Figure 11 shows the kernel detachment of corn ears impacted with a velocity of $5.0 \mathrm{~m} \mathrm{~s}^{-1}$ at a moisture content 23.4 and $30.6 \%$. It may be seen that the detached

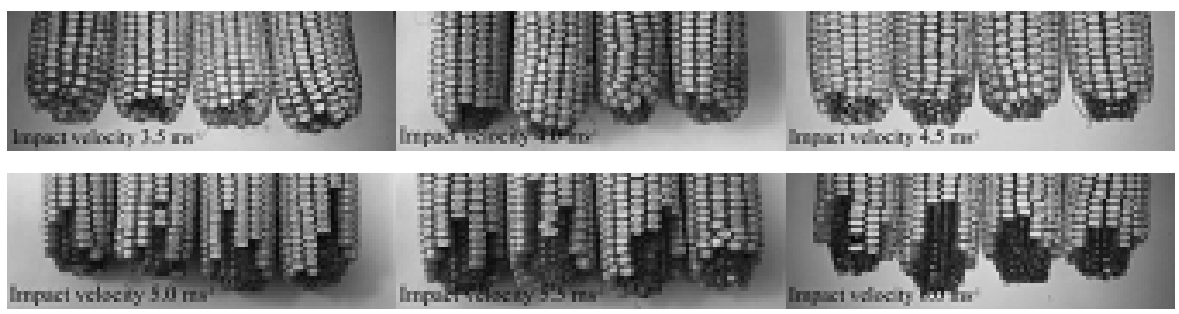

Fig. 10. Features of kernel detachment under different impact velocities at a moisture content of $18.5 \%$. 


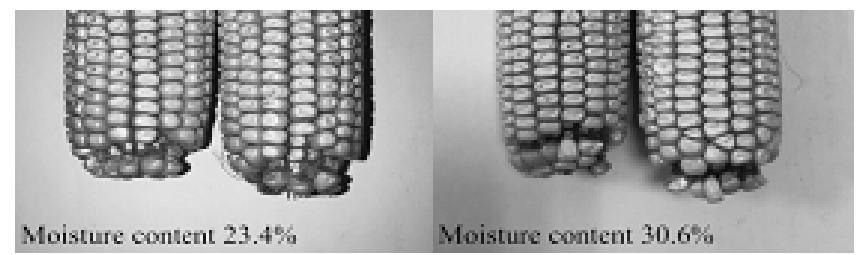

Fig. 11. Features of kernel detachment under an impact velocity of $5.0 \mathrm{~m} \mathrm{~s}^{-1}$ at different moisture contents.

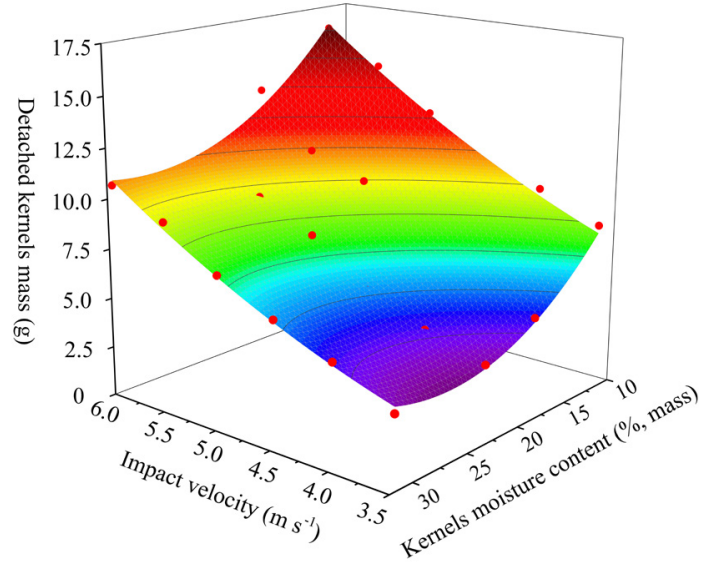

Fig. 12. Interaction effect of impact velocity and moisture content on the detached kernel mass.

kernels turn out to be the only ones out of contact with the impacting plate as a result of an increase in moisture content. In other words, the forces applied to kernels out of contact with the impacting plate met Inequality (2). But for the kernels in contact with the impacting plate, Inequality (1) was not fulfilled. Logically, this was in accordance with the previous conclusion that the moisture content had a significant effect on the strength of the kernel pedicels.

Hence, the detachment of the kernels in the impact was influenced by the joint action of the impact velocity and kernel moisture content. In order to establish a model of the interaction of the effect of the impact velocity and moisture content on the detached mass of the kernels, full factorial tests were conducted with the index of the detached kernel mass. The impact velocities were between 3.5 and $6.0 \mathrm{~m} \mathrm{~s}^{-1}$, the moisture contents were between 11.8 and $30.6 \%$. The data points in Fig. 12 represent the mass values of the detached kernels. The mass of the detached kernels increased with an increase in the impact velocity and a decrease in the kernel moisture content. In addition, a polynomial 3D surface was obtained through the data points, which was in accordance with the result of Srison et al. (2016). The fitted surface may be expressed by the following equation:

$$
\begin{gathered}
m_{\text {det }}=0.3428 v_{\mathrm{I}}^{2}+0.3959 v_{\mathrm{I}}+0.0229 C_{\mathrm{M}}^{2}-1.0953 C_{\mathrm{M}} \\
-0.0293 v_{\mathrm{I}} C_{\mathrm{M}}+13.5834,
\end{gathered}
$$

where: $m_{\text {det }}$ is the mass of the detached kernel, $\mathrm{g}$; $v_{\mathrm{I}}$ is the impact velocity, $\mathrm{m} \mathrm{s}^{-1} ; C_{\mathrm{M}}$ is the kernel moisture content, $\%$, mass.

\section{CONCLUSIONS}

The detachment of corn kernels was found to be closely related to the dissipated momentum, which may be characterized and calculated with the impact parameters including impact velocity, impact time, peak acceleration, impact impulse, and rebound velocity. Also, the moisture content played an important role in the connection strength between the corn kernels and the corn cob.

1. The acceleration integral was directly related to the impact velocity. As the impact time changed slightly with a decreasing trend, the peak acceleration increased significantly with the increase in the impact velocity. The rebound time and rebound velocity increased distinctly with the impact velocity. The best-fit models for effects of the rebound time and the rebound velocity on the impact velocity were 2 -th curves.

2. The value of acceleration integral remained constant as the kernel moisture content changed from 11.8 to $30.6 \%$ with the impact velocity of $5.0 \mathrm{~m} \mathrm{~s}^{-1}$. The rebound velocity showed significant improvement as the moisture content increased.

3. The dissipated momentum showed a similar trend with the mass of the detached kernels, which increased with the impact velocity and decreased with moisture content. When the moisture content remained at $18.5 \%$, the dissipated momentum showed an upward trend with a quadratic function as the mass of the detached kernels shows. Similarly, when the impact velocity was fixed at 5 $\mathrm{m} \mathrm{s}^{-1}$, the dissipated momentum showed a declining trend with the increase in moisture content, same as the line representing the detached kernels mass.

4. The detachment of the kernels had different features depending on the variation in the impact velocity and moisture content. Considering the parameters of the impacts, it may be concluded that the detachment of the kernels was affected by the stress on the kernels as well a $s$ the mechanical properties of the kernels. Thus, a binary quadratic equation and quadric surface were obtained for fitting the interaction effect of the impact velocity and moisture content on kernel detachment.

Conflict of interest: The Authors do not declare conflict of interest. 


\section{REFERENCES}

Ajayi O.A. and Clarke B., 1997. High velocity impact of maize kernels. J. Agric. Eng. Res., 67, 97-104. https://doi.org/10.1006/jaer.1997.0156

Boydas M.G., Ozbek I.Y., and Kara M., 2014. An efficient laser sensor system for apple impact bruise volume estimation. Postharvest Biol. Tec., 89, 49-55. https://doi.org/10.1016/j.postharvbio.2013.11.005

Burkhardt T.H. and Stout B.A., 1974. Laboratory Investigations of Corn Shelling. Tran. ASAE, 17, 11-14.

Cerruto E., Aglieco C., Gottschalk K., Surdilovic J., Manetto G., and Geyer M., 2015. FEM Analysis of effects of mechanical impact parameters on fruit characteristics. Agric. Eng. Int. CIGR J., 17(3), 430-440.

Figueroa J.D.C., Hernández Z.J.E., Véles M.J.J., Rayas-Duarte P., Martínez-Flores H.E., and Ponce-García N., 2011. Evaluation of degree of elasticity and other mechanical properties of wheat kernels. Cereal Chem., 88(1), 12-18. https://doi.org/10.1094/cchem-04-10-0065

Fu J., Chen Z., Han L., and Ren L., 2018. Review of grain threshing theory and technology. Int. J. Agric. Biol. Eng., 11(3), 12-20.

Geyer M.O., Praeger U., König C., Graf A., Truppel I., Schlüter O., and Herold B., 2009. Measuring behavior of an acceleration measuring unit implanted in potatoes. T. ASABE, 52(4), 1267-1274. https://doi.org/10.13031/2013.27770

Hanna H.M., Kohl K.D., and Haden D.A., 2002. Machine losses from conventional versus narrow row corn harvest. Appl. Eng.Agric., 18(4), 405-409. https://doi.org/10.13031/2013.8744

He J., 2007. Biomimetic surface on snapping rolls with lower damage action and simulation of no-row feed-in mechanism of maize harvesters (in Chinese). Ph.D. Thesis, Jilin University, Changchun, China.

Jiménez-Jiménez F., Castro-García S., Blanco-Roldán G.L., Agüera-Vega J., and Gil-Ribes J.A., 2012. Nondestructive determination of impact bruising on table olives using ViseNIR spectroscopy. Biosyst. Eng., 113, 371-378. https://doi.org/10.1016/j.biosystemseng.2012.09.007

Kalkan F., Kara M., Bastaban S., and Turgut N., 2011. Strength and frictional properties of popcorn kernel as affected by moisture content. Int. J. Food Prop., 14, 1197-1207. https://doi.org/10.1080/10942911003637319

Li X., Du Z., Ma Y., Gao C., and Ma F., 2014. Discrete analysis of maize ear at different impact head. A. M. M., 651-653, 323-327. https://doi.org/10.4028/www.scientific.net/ amm.651-653.323

Li Z., Liu J., Li P., and Yin J., 2009. Study on the collisionmechanical properties of tomatoes gripped by harvesting robot fingers. Afr. J. Biotechnol., 8(24), 7000-7007.

Lien C.C. and Ting C.H., 2014. Assessing guava maturity by statistical analyses of dropped fruit impact responses. Postharvest Biol. Tec., 95, 20-27. https://doi.org/10.1016/j.postharvbio.2014.03.013

Lin F. and Zhang Y., 2017. An impulse based model for impact between two concrete blocks. Int. J. Impact Eng., 107, 96-107. https://doi.org/10.1016/j.ijimpeng.2017.04.019

Lu F., Ishikawa Y., Kitazawa H., and Satake T., 2010. Measurement of impact pressure and bruising of apple fruit using pressure-sensitive film technique. J. Food Eng., 96, 614-620. https://doi.org/10.1016/j.jfoodeng.2009.09.009
Paulsen M.R., de Assis de Carvalho Pinto F., de Sena Jr D.G., Zandonadi R.S., Ruffato S., Gomide Costa A., Ragagnin V.A., and Danao M.-G.C., 2013. Measurement of Combine Losses for Corn and Soybeans in Brazil. Appl. Eng. Agric., 30(6), 841-855. https://doi.org/10.13031/aim.20131570965

Petrů M., Novák O., Herák D., and Simanjuntak S., 2012. Finite element method model of the mechanical behaviour of Jatropha curcas L. seed under compression loading. Biosyst. Eng., 111, 412-421.

https://doi.org/10.1016/j.biosystemseng.2012.01.008

Qian Z., Jin C., and Zhang D., 2017. Multiple frictional impact dynamics of threshing process between flexible tooth and grain kernel. Comput. Electron. Agr., 141, 276-285. https://doi.org/10.1016/j.compag.2017.07.022

Shahbazi F., 2011. Impact damage to chickpea seeds as affected by moisture content and impact velocity. Appl. Eng. Agric., 27(5), 771-775. https://doi.org/10.13031/2013.39557

Shahbazi F., Saffar A., and Analooei M., 2011. Mechanical damage to navy beans as affected by moisture content, impact velocity and seed orientation. Qual. Assur. Saf. Crop., 3, 205-211. https://doi.org/10.1111/j.1757-837x.2011.00114.x

Singh S.S., Finner M.F., Rohatgi P.K., Buelow F.H., and Schaller M., 1991. Structure and mechanical properties of corn kernels: a hybrid composite material. J. Mat. Sci., 26, 274-284. https://doi.org/10.1007/bf00576063

Srison W., Chuan-Udom S., and Saengprachatanarak K., 2016. Effects of operating factors for an axial-flow corn shelling unit on losses and power consumption. Agric. Natural Res., 50, 421-425.

https://doi.org/10.1016/j.anres.2016.05.002

Srivastava A.K., Herum F.L., and Stevens K.K., 1976. Impact parameters related to physical damage to corn kernel. tran. ASAE, 19(6),1147-1151.https://doi.org/10.13031/2013.36191

Stropek Z. and Golacki K., 2013. The effect of drop height on bruising of selected apple varieties. Postharvest Biol. Tec., $85,167-172$. https://doi.org/10.1016/j.postharvbio.2013.06.002

Stropek Z. and Golacki K., 2015. A new method for measuring impact related bruises in fruits. Postharvest Biol. Tec., 110, 131-139. https://doi.org/10.1016/j.postharvbio.2015.07.005

Stropek Z. and Golacki K., 2016. Quantity assessment of plastic deformation energy under impact loading conditions of selected apple cultivars. Postharvest Biol. Tec., 115, 9-17. https://doi.org/10.1016/j.postharvbio.2015.12.011

Studman C.J., 2001. Computers and electronics in postharvest technology - a review. Comput. Electron. Agr., 30, 109-124.

Špokas L., Steponavičius D., and Petkevičius S., 2008. Impact of technological parameters of threshing apparatus on grain damage. Agronomy Research, 6, 367-376.

Wang G., Jia H., Tang L., Zhuang J., Jiang X., and Guo M., 2016. Design of variable screw pitch rib snapping roller and residue cutter for corn harvesters. Int. J. Agric. Biol. Eng., 9(1), 27-34.

Xu L.Z., Li Y.M., Ma Z., Zhao Z., and Wang C.H., 2013. Theoretical analysis and finite element simulation of a rice kernel obliquely impacted by a threshing tooth. Biosyst. Eng., 114, 146-156. https://doi.org/10.1016/j.biosystemseng.2012.11.006 
Yan H., 2009. Working mechanism and experimental research on key components of vertical roll-type corn harvester (in Chinese). Ph.D. Thesis, Jilin University, Changchun, China.

Yang L., Cui T., Qu Z., and Zhang D.X., 2016. Development and application of mechanized maize harvesters. Int. J. Agric. Biol. Eng., 9(3), 15-28.

Yang Y. and Schrock M.D., 1994. Analysis of grain kernel rebound motion. Tran. ASAE, 37(1), 27-31.

https://doi.org/10.13031/2013.28049
Yousefi S., Farsi H., and Kheiralipour K., 2016. Drop test of pear fruit: Experimental measurement and finite element modelling. Biosyst. Eng., 147, 17-25. https://doi.org/10.1016/j.biosystemseng.2016.03.004

Zareiforoush H., Komarizadeh M.H., and Alizadeh M.R., 2010. Effects of crop-machine variables on paddy grain damage during handling with an inclined screw auger. Biosyst. Eng., 106, 234-242. https://doi.org/10.1016/j.biosystemseng.2010.02.008

Zhao W., 2012. Research of combined type of spiral bar tooth threshing mechanism for seed corn (in Chinese). Ph.D. Thesis, Northwest A\&F University, Yangling, China. 